\title{
Auguste de Staël, Correspondance. Lettres à sa mère (1805-1816)
}

\section{Catherine Thomas}

\section{Q OpenEdition}

10 Journals

\section{Édition électronique}

URL : http://journals.openedition.org/studifrancesi/1533

DOI : 10.4000/studifrancesi. 1533

ISSN : 2421-5856

Éditeur

Rosenberg \& Sellier

\section{Édition imprimée}

Date de publication : 1 novembre 2014

Pagination : 609-610

ISSN : 0039-2944

\section{Référence électronique}

Catherine Thomas, «Auguste de Staël, Correspondance. Lettres à sa mère (1805-1816) », Studi Francesi [En ligne], 174 (LVIII | III) | 2014, mis en ligne le 01 novembre 2014, consulté le 18 septembre 2020. URL : http://journals.openedition.org/studifrancesi/1533; DOI : https://doi.org/10.4000/studifrancesi. 1533

Ce document a été généré automatiquement le 18 septembre 2020.

\section{(c)}

Studi Francesi è distribuita con Licenza Creative Commons Attribuzione - Non commerciale - Non opere derivate 4.0 Internazionale. 


\title{
Auguste de Staël, Correspondance. Lettres à sa mère (1805-1816)
}

\author{
Catherine Thomas
}

\section{RÉFÉRENCE}

AUGUSTE DE STAËL, Correspondance. Lettres à sa mère (1805-1816) en grande partie inédites, transcrites, présentées et annotées par Othenin d'HAUSSONVILLE et Lucia OMACINI, Paris, Honoré Champion, «Tournant des Lumières», 2013, pp. 477.

1 Les lettres d'Auguste de Staël à sa mère, conservées dans les archives du château de Coppet, sont réunies pour la première fois par Othenin d'Haussonville, descendant de Mme de Staël et propriétaire de ce château, et Lucia Omacini, qui travaille sur son œuvre. Si la plupart des lettres d'Auguste entre 1805, année où il entre à la pension Thurot à Paris, et 1816, quelques mois avant la mort de sa mère, ont été retrouvées trois cent soixante lettres exactement -, celles que Mme de Staël a écrites à son fils durant cette longue période ont été en grande partie détruites ou perdues: seules soixante-six de ces lettres figurent dans ces deux volumes de correspondance.

2 C'est donc Auguste essentiellement qui tient la plume, mais il n'est question que de sa mère tout au long de ses lettres. Dans le premier volume (1805-1813), il lui rend minutieusement compte des nombreuses démarches qu'il effectue à Paris pour tenter de faire progresser ses affaires. Il s'agit surtout de tenter de révoquer l'ordre d'exil qui la touche ou, tout au moins, lorsque cela se révèle impossible, d'en atténuer la rigueur, et de demander le remboursement des deux millions prêtés au Trésor royal par Necker en 1778; mais il faut aussi s'employer à ramener Benjamin Constant auprès d'elle et à étouffer le bruit que pourrait faire le mariage de ce dernier, en juin 1808, avec Charlotte von Hardenberg. À travers les lettres du fils s'entendent précisément les injonctions de la mère à aller voir l'une ou l'autre de ses connaissances, par amitié ou pour la servir dans ses tentatives de retour en France, ainsi que ses manœuvres pour s'attacher Constant. Puis, lorsqu'Auguste grandit, il devient «protecteur protégé» (t. I, 
p. 381) et conseille Germaine de Staël dans la gestion de ses affaires, en particulier lors de l'interdiction de De l'Allemagne ou lors de sa fuite en Suède, qu'il estime toujours trop lente dans sa peur de voir sa mère rattrapée par les autorités.

3 Le second volume de cette correspondance (1813-1816) montre encore Auguste tout occupé de la "grande affaire» (t. II, p. 521) que constitue la dette de Necker, dont le remboursement est d'autant plus attendu qu'il conditionne désormais le mariage d'Albertine avec Victor de Broglie. Auguste expose également avec force détails la façon dont il gère le patrimoine de sa mère pendant son absence. Mais l'intérêt principal de ce volume réside surtout dans le témoignage qu'il nous offre d'une période agitée et incertaine de l'histoire de France: aide de camp du Prince royal à Liège, puis installé à Paris où il fréquente les personnalités les plus marquantes de son temps, Auguste tient sa mère au courant des nouvelles militaires et politiques, décrit l'atmosphère de Paris sous la Restauration et rapporte les «bruits de salon» (t. II, p. 621) qui agitent la société d'alors. Si l'on entend encore les continuelles requêtes de Mme de Staël à travers les réponses de son fils, il ose parfois quelques reproches: elle se trompe sur la personnalité véritable de son futur gendre Victor, ne tient pas suffisamment compte de l'analyse qu'Auguste lui offre de la situation politique intérieure: «en vérité, lui écrit-il en octobre 1815, c'est un exemple bien frappant de l'impossibilité de connaître un pays dont on a été longtemps éloigné que de voir le premier esprit du siècle devenu en quelque sorte étranger à l'état de la question» (t. II, p. 647).

4 Ainsi suivons-nous, à travers les lettres d'Auguste, la vie de Mme de Staël et les éléments de son quotidien, comme les comédies qu'elle joue à Coppet, ses divers déplacements, la façon dont elle est partout reçue, les personnes qu'elle fréquente, les démarches qu'elle entreprend; mais nous percevons aussi les sentiments et les souffrances qui peuvent être les siens au gré des situations qu'elle traverse. Nous découvrons en outre, à travers ses quelques lettres et les réponses de son fils, son caractère extrêmement autoritaire, sa dureté même, puisqu'elle accable inlassablement Auguste de reproches: il manque de sentiments, ne travaille pas assez, néglige les affaires qu'elle lui confie, dépense trop, s'amuse, l'oublie. Lui se montre accablé par ces perpétuelles critiques, auxquelles il oppose des protestations d'amour et d'admiration sans cesse renouvelées: «ce n'est que dans mon affection pour toi que je suis en vie» (t. I, p. 290), assure-t-il en décembre 1809, et encore, sept ans plus tard: «il n'y a rien de plus injuste que la pensée que tu ne m'es pas nécessaire, tandis qu'il n'y a pas de jour que je ne répète à moi-même et aux autres que je ne puis trouver sans toi ni amusement ni intérêt durable à rien» (t. II, p. 734). Sur celui qui écrit, cette correspondance nous apprend finalement peu de choses: son humeur de nature plutôt sombre varie au gré des lettres, tendres ou sévères, qu'il reçoit de sa mère. Jeune homme «quelque fois un peu doctoral» (t. I, p. 113) selon les termes de celle-ci, il se révèle brillant dans ses études, plus porté vers la solitude que vers les mondanités, habile gestionnaire financier, fils aimant et ami loyal. De la passion qu'il voue à Mme Récamier ou de ses relations avec Mme de Sainte Aulaire, nous n'apprenons pour ainsi dire rien, tant il parait difficile pour sa destinataire de voir sous la plume de son fils un autre nom féminin que le sien.

5 L'appareil critique de cette correspondance, très bien élaboré, accompagne le lecteur en resituant les lettres dans un contexte historique et privé qui en éclaire la lecture: en particulier le recours à la correspondance générale de Mme de Staël, fréquent dans les notes, est toujours le bienvenu et permet de mieux comprendre la pensée de la 
destinataire et cette relation hors norme que dévoilent les lettres d'Auguste. Une courte présentation par Lucia OMACINI (pp. IX-XXII) et une biographie fort utile permettent d'emblée de mieux connaître l'aîné des enfants de Mme de Staël. Les lettres sont ensuite regroupées en vingt périodes introduites par un rappel des circonstances qui éloignent à ces moments-là Auguste de sa mère, et des principaux événements qui marquent alors leur vie. Le deuxième volume s'achève par une suite de notices sur les personnages cités, une liste des ouvrages cités, une bibliographie et un index des noms propres. L'ensemble forme un document riche permettant de mieux connaître la vie, la pensée, l'entourage de Mme de Staël, mais également de se plonger dans une période chaotique de l'histoire de France. Nous serons surtout sensibles à la relation forte et, du côté d'Auguste, presque désespérée que ces lettres révèlent; elle témoigne encore, de façon particulièrement frappante, de la puissante personnalité de Mme de Staël. 